\title{
Delayed-onset post-operative keratitis and endophthalmitis caused by Exophiala oligosperma
}

\author{
Laurie W. van der Merwe ${ }^{1 *}$, Dawood da Costa $^{2}$, Kessendri Reddy ${ }^{2}$ and David Meyer ${ }^{1}$
}

\begin{abstract}
A case of delayed-onset post-cataract-surgery keratitis and endophthalmitis, caused by the melanin-producing fungus Exophiala oligosperma, is presented. The patient presented with an infection at the corneal side-port wound 5 months after an uneventful phacoemulsification surgery. Despite pars plana vitrectomy and combination antifungal treatment, the patient required an evisceration of the globe. Limited clinical information is available about the treatment of eye infections caused by this organism.
\end{abstract}

Keywords: Fungal endophthalmitis, Fungal keratitis, Exophiala oligosperma, Delayed-onset endophthalmitis

\section{Introduction}

Delayed-onset post-operative endophthalmitis can be a frustrating entity to manage. Fungi, a frequent cause of this syndrome, may replicate slowly, can be difficult to culture and often respond poorly to antifungal agents. We present a case of delayed-onset post-operative keratitis and endophthalmitis caused by Exophiala oligosperma in a resource-limited population.

\section{Presentation}

A 75-year-old female patient presented to the ophthalmology outpatient clinic at Tygerberg Hospital, South Africa, 1 week after the spontaneous onset of pain and photophobia in her left eye. She was known to have type II diabetes with an $\mathrm{HbA1C}$ of $8.2 \%$ and ischaemic heart disease. She was HIV-negative and did not use immunosuppressive therapy. The patient underwent an uncomplicated phacoemulsification procedure with an intraocular lens (IOL) implantation of the affected eye 5 months before the onset of her symptoms.

\footnotetext{
* Correspondence: lauriewiid.vdmerwe@gmail.com

${ }^{1}$ Division of Ophthalmology, Tygerberg Academic Hospital, University of Stellenbosch, Cape Town, South Africa

Full list of author information is available at the end of the article
}

On examination, her right (unaffected) eye had an uncorrected distance visual acuity (VA) of 0.9 , a normal pseudophakic anterior and posterior segment examination and no diabetic retinopathy. The VA in the left (affected) eye was counting fingers at $1 \mathrm{~m}$, which improved to Snellen VA of 0.2 with a pinhole. No blepharospasm or chemosis was present. Ciliary injection was noted, with a white corneal stromal infiltrate at the seven o'clock side-port wound, without epithelial staining. The infiltrate was round and less than $1 \mathrm{~mm}$ diameter, with surrounding corneal oedema and fine corneal precipitates. The anterior chamber was formed, without the presence of any cells or flare, and no precipitates were visible on the intraocular lens. She did not have a relative afferent pupillary defect (RAPD).

With the diagnosis of keratitis, topical ciprofloxacin $0.3 \%$ was prescribed, with frequent follow-up. Although symptoms improved initially, the infiltrate persisted, and a possible immunological process was suspected due to the peripheral intrastromal location and lack of an epithelial defect. The infiltrate was too small and deep to get an adequate sample, and a corneal biopsy was not considered at this stage because the infiltrate still appeared to be benign. In addition to the ciprofloxacin, a topical steroid-antibiotic combination of polymyxin B,

\section{Springer Open}

๑ The Author(s). 2021 Open Access This article is licensed under a Creative Commons Attribution 4.0 International License, which permits use, sharing, adaptation, distribution and reproduction in any medium or format, as long as you give appropriate credit to the original author(s) and the source, provide a link to the Creative Commons licence, and indicate if changes were made. The images or other third party material in this article are included in the article's Creative Commons licence, unless indicated otherwise in a credit line to the material. If material is not included in the article's Creative Commons licence and your intended use is not permitted by statutory regulation or exceeds the permitted use, you will need to obtain permission directly from the copyright holder. To view a copy of this licence, visit http://creativecommons.org/licenses/by/4.0/. 
neomycin and dexamethasone (Maxitrol $\left.{ }^{\circ}\right)$ was prescribed with close clinical follow-up. The patient reported further improvement in her symptoms, but the infiltrate remained unchanged. Three weeks after defaulting on a scheduled appointment, the patient returned to the clinic with enlargement of the infiltrate at the seven o'clock side-port site, a new infiltrate at the two o'clock side-port wound and an anterior-chamber reaction with $1+$ flare and $2+{\text { cells. The } \text { Maxitrol }^{\circ} \text { was }}^{\circ}$ stopped, and the antibiotic prescription was changed to fortified topical ceftazidime $5 \%$ and cefazolin $5 \%$. A corneal swab and scrape (sample set 1 - see Table 1) from the seven o'clock side-port wound was taken at the slit lamp and sent for microscopy, culture and sensitivity testing, but no organisms were cultured on this sample. Her condition continued to deteriorate, and she developed a slither of hypopyon and 1+ vitreous cells with a VA of counting fingers at $1 \mathrm{~m}$ (see Fig. 1). She was then diagnosed with delayed-onset post-operative endophthalmitis and admitted to hospital.

On admission vitreous aspirate and corneal scrape samples (sample set 2) were taken, after which she was treated with intravitreal vancomycin $(1 \mathrm{mg}$ in $0.1 \mathrm{ml})$, ceftazidime ( $2 \mathrm{mg}$ in $0.1 \mathrm{ml}$ ) and dexamethasone $(0.4 \mathrm{mg}$ in $0.1 \mathrm{ml})$. At this stage the corneal infiltrate had progressed to form an intrastromal abscess, which was drained and sent for microscopy, culture and sensitivity testing, together with the vitreous and corneal samples (as part of sample set 2). After administration of the intravitreal drugs, the anterior chamber reaction improved, pain resolved despite persistence of $1+$ vitreous cells and her unaided VA improved to 0.4 . Ten days after obtaining sample set 2, the fungal and bacterial cultures for both aerobic and anaerobic organisms were confirmed to be negative, and the patient was discharged from hospital. The clinical improvement in symptoms and the negative culture results were interpreted as a favourable response to the intravitreal therapy at this point.

However, 3 weeks after being discharged, she returned to the clinic with a complaint of recurrent pain and decreased vision in the affected eye. Her vision has deteriorated to detection of hand movements only. A view of the retina was obscured by hypopyon, $4+$ cells and $2+$ flare, an enlarged temporal corneal infiltrate, corneal oedema and 2+ vitreous cells (Fig. 2). Review of the fungal culture of the vitreous sample (sample set 2) revealed the growth of a filamentous fungus, Exophiala oligosperma. This was confirmed with internal transcribed spacer 2 (ITS2) ribosomal DNA sequencing of the cultured fungal isolate (Fig. 3). The patient was readmitted and started on treatment with oral voriconazole $200 \mathrm{mg}$ twice daily, topical amphotericin B $0.15 \%$ hourly (later replaced by natamycin 5\%) and topical fortified vancomycin 5\% and ceftazidime 5\% hourly.

Despite therapy, her eye continued to deteriorate. Pars plana vitrectomy (PPV), corneal abscess drainage and an anterior-chamber washout were performed. The IOL and capsular bag were not removed. Intravitreal amphotericin B $(5 \mu \mathrm{g}$ in $0.1 \mathrm{ml})$, vancomycin and ceftazidime were given intraoperatively. Specimens from the cornea, anterior chamber and vitreous (sample set 3), taken during surgery, were sent for bacterial and fungal microscopy, culture and sensitivity analysis. On the first day post-PPV, the patient had a fibrinous anterior chamber reaction, and on the second day after surgery the hypopyon recurred. During hospitalisation, she received four dosages of intravitreal amphotericin B $(5 \mu \mathrm{g}$ in $0.1 \mathrm{ml})$, vancomycin and ceftazidime and two dosages of subconjunctival amphotericin $B$, with a repeat vitreous aspiration for fungal microscopy, culture and sensitivity (sample set 4) at the time of the last intravitreal injection.

Two weeks post-PPV her vision has deteriorated to light perception only. She developed a dense RAPD, recurrence of the intrastromal abscesses at both side-port wounds, a large, localised anterior-chamber exudate collection and persistent pain (Fig. 4). She did not respond to the combination antifungal treatment. All the samples taken during PPV (sample set 3) also cultured E. oligosperma. The management options were discussed with the patient, and she opted for an evisceration. The evisceration was performed 8 months after undergoing cataract surgery and 19 days after commencing antifungal treatment.

\section{Microbiology}

Molecular identification was performed on the cultured isolate (Fig. 3). Genomic DNA was extracted using the

Table 1 Summary of samples taken and culture results

\begin{tabular}{lll}
\hline Date & Samples & Culture results \\
\hline $\mathbf{0 9 / 0 5 / 2 0 1 9}$ & Sample set $\mathbf{1}$ - corneal swab and scrape & No growth \\
$\mathbf{2 8 / 6 / 2 0 1 9}$ & $\begin{array}{l}\text { Sample set } \mathbf{2} \text { - Vitreous aspirate and corneal swab, scrape, } \\
\text { and intrastromal exudate aspiration }\end{array}$ & Cultured Exophiala oligosperma on the vitreous aspirate \\
$\mathbf{3 1 / 7 / 2 0 1 9}$ & $\begin{array}{l}\text { Sample set } \mathbf{3} \text { - vitreous aspirate, anterior chamber aspirate } \\
\text { and cornea swab }\end{array}$ & Cultured Exophiala oligosperma on all 3 samples. \\
$\mathbf{0 8 / 0 8 / 2 0 1 9}$ & Sample set $\mathbf{4}$ - Vitreous aspirate & No organisms cultured \\
\hline
\end{tabular}




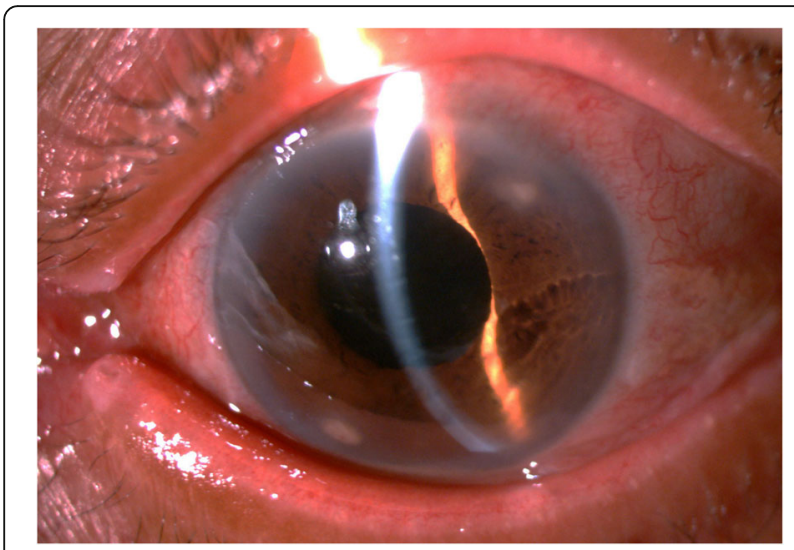

Fig. 1 Infiltrate at corneal side-port wounds in left eye

Quick-DNA Fungal/Bacterial Kit (Zymo Research, USA) according to the manufacturer's guidelines. A polymerase chain reaction amplification was performed, targeting the internal transcribed spacer region using the ITS2 primers [1]. The obtained fragment sequence was compared with the available sequences in the GenBank using the Basic Local Alignment Search Tool (BLAST) [2]. A BLAST search executed on the sequenced isolate in the National Centre for Biotechnology Information database identified the isolate as E. oligosperma with a $>99 \%$ homology.

Antifungal susceptibility testing on the cultured isolate of E. oligosperma was done at the Mycology Reference Laboratory at the National Institute for Communicable Diseases. The minimum inhibitory concentrations (MIC) were determined by gradient diffusion testing ( $\mathrm{E}$ test, Biomerieux, USA), and tabulated (Table 1). Clinical breakpoint interpretive criteria do not currently exist for E. oligosperma.

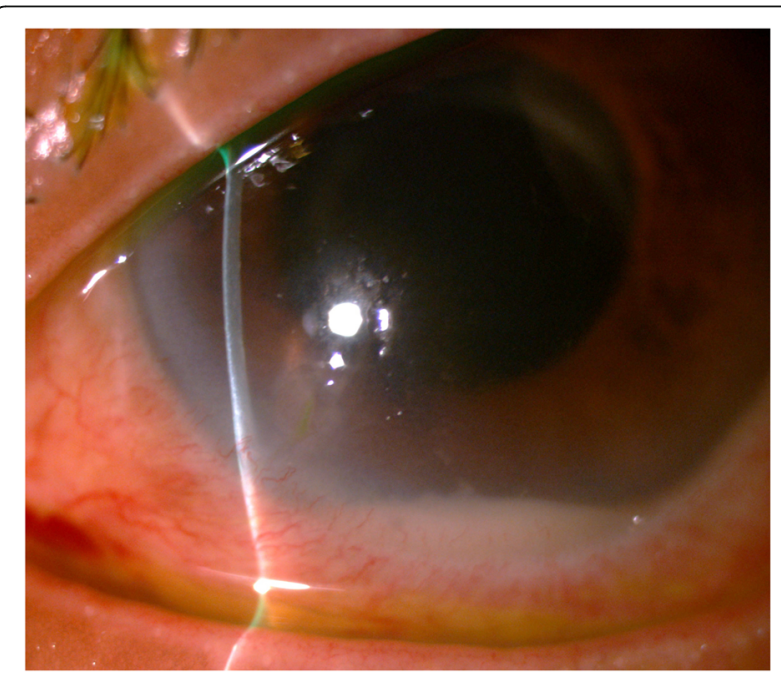

Fig. 2 Enlargement of hypopyon and corneal infiltrate in left eye

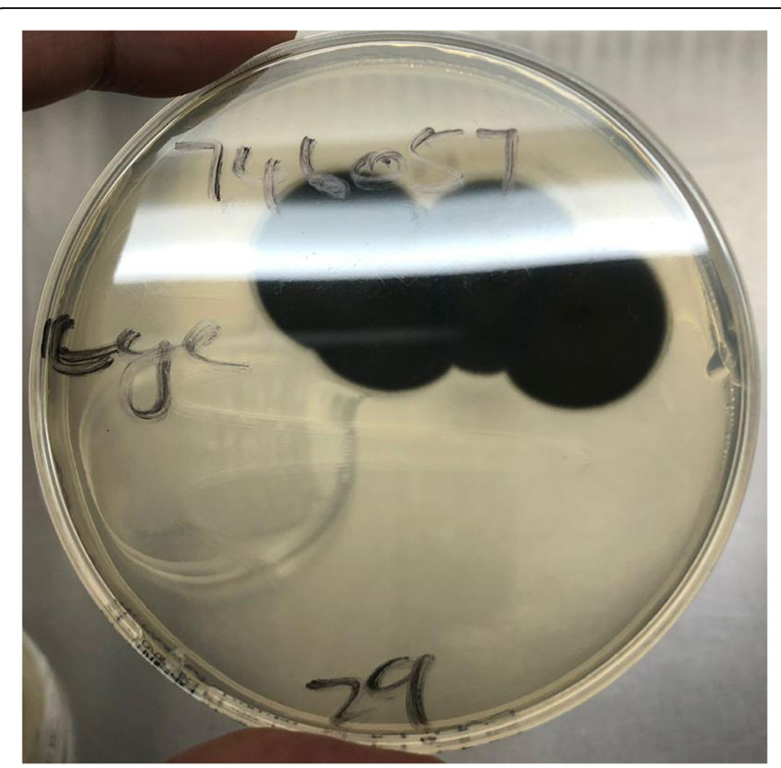

Fig. 3 Culture plate of melanin producing Exophiala oligosperma

\section{Discussion}

Delayed-onset post-operative endophthalmitis is mainly caused by Propionibacterium species followed by coagulase-negative staphylococci, Corynebacterium species, Cutibacterium acnes and fungi [3-9]. Anand et al. reported $21.8 \%$ of post-operative endophthalmitis cases in India to be caused by fungi, but the incidence is expected to be lower in the rest of the world [7].

Exophiala species are filamentous fungi and form part of a group of dematiaceous moulds. These moulds are darkly pigmented due to the production of melanin in their cell walls, which is also speculated to increase the virulence of these organisms [10, 11]. Exophiala species are emerging pathogens known to cause disease in immunocompromised patients, such as people who received transplants, people with HIV and people with

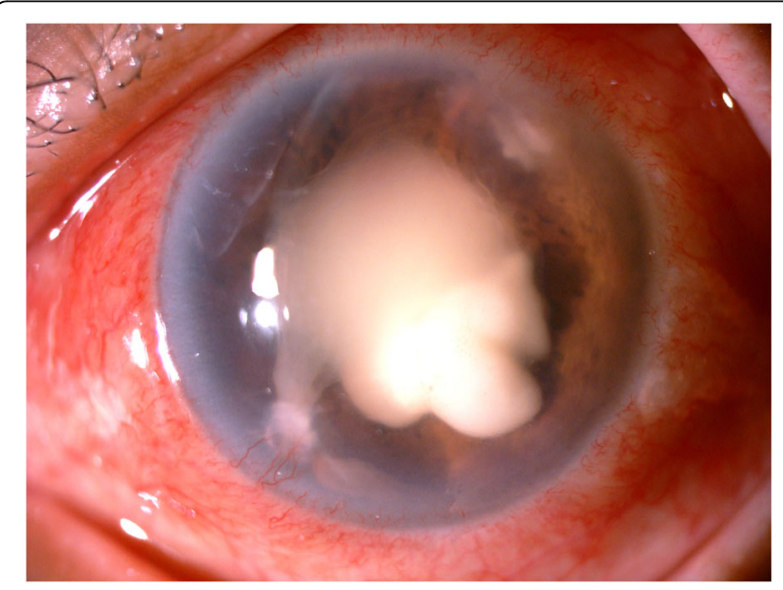

Fig. 4 Advanced endophthalmitis prior to evisceration of left eye 
diabetes [11, 12]. Exophiala species are associated with nutrient-poor and toxic environments. They have been isolated in steam baths and toxic mines [11]. These organisms are known to cause skin and soft tissue infections, pneumonia, keratitis, septic arthritis, endocarditis and neurological infections, with a predilection to form granulomas and microabcesses $[11,12]$. It is difficult to distinguish microbiologically between the different species of Exophiala, as they show very little morphological differentiation $[11,12]$. Chakrabarti et al. ascribed 10.5\% of fungal endophthalmitis cases to other melaninproducing fungi, but were not able to culture Exophiala species in a single case [13].

Isolated case reports of Exophiala infections involving the eye were found in the English literature. Homa et al. conducted a literature review of cases of Exophiala eye infections, documented from 1990 to 2018. They reviewed seven cases of keratitis, one case of a subconjunctival mycetoma and seven cases of endophthalmitis [14], and reported on infections caused by Exophiala dermatitidis, Exophiala jeanselmei and Exophiala phaeomuriformis, but there was no report of an E. oligosperma infection. Based on these case reports of Exophiala eye infections, pre-existing medical conditions may possibly increase the chances of therapeutic failure. Infections were eradicated in six of the seven cases of keratitis. Conversely, cases of subconjunctival mycetoma and endophthalmitis had poor visual outcomes.

In another case report on Exophiala phaeomuriformis keratitis, an elderly Caucasian female with a persistent epithelial defect responded favourably to topical amphotericin B and oral fluconazole [15].

Exophiala were not reliably differentiated into species before the advent of widespread molecular testing; as a result, misclassification or under-reporting is plausible. The initial medical management of fungal endophthalmitis consists of antifungal drugs, which may be administered topically, intravitreally or systemically, with up to three different antifungals used simultaneously [5, 8, 16-18].

Oral voriconazole has been found to attain intraocular levels of $1.13 \mu \mathrm{g} / \mathrm{ml}$ in the aqueous and $0.81 \mu \mathrm{g} / \mathrm{ml}$ in the vitreous of non-inflamed eyes [19]. In vitro susceptibility testing has previously shown antifungals to have the following MIC values for E. oligosperma: $0.5 \mu \mathrm{g} / \mathrm{ml}$ for voriconazole; $0.25 \mu \mathrm{g} / \mathrm{ml}$ for itraconazole; $0.25 \mu \mathrm{g} / \mathrm{ml}$ for amphotericin B; $0.25 \mu \mathrm{g} / \mathrm{ml}$ for caspofungin and $0.25 \mu \mathrm{g}$ / $\mathrm{ml}$ for natamycin [16].

The antifungal MIC levels were presumably achieved in our patient, and a better response to the combination treatment was expected. Factors that possibly contributed to the poor response are the initial administration of steroid therapy; the primary site of infection being limited to the cornea; the patient's underlying diabetes and the unknown effect of ocular inflammation on the
MIC levels of the antifungal medication. The vitreous sample taken before evisceration (sample set 4) did, however, not culture any fungi.

The topical steroid therapy and single dose of intravitreal dexamethasone might have contributed to the poor outcome. The diagnosis of a fungal keratitis was not initially considered likely because the first corneal swab (sample set 1) did not culture any organisms and there were no clinical signs indicative of a fungal infection. The length of time involved in culturing the fungus significantly hampered the process of diagnosing delayedonset endophthalmitis.

The prognosis for post-operative fungal endophthalmitis is notoriously poor. Chakrabarti et al. found that $52 \%$ of a sample of 53 patients with this diagnosis had a final outcome of counting fingers or worse [13]. In another report, only two from seven cases of endophthalmitis secondary to Exophiala infection had improved VA after treatment (voriconazole, fluconazole and surgical intervention for both); the remaining five cases all had unfavourable outcomes [14]. Homa et al. argued that prompt, targeted surgical removal of the infected tissue or IOL improved outcomes; this could be ascribed to the tendency of Exophiala species to form localised abscesses. It is suggested that intravitreal voriconazole has better outcomes than intravitreal amphotericin B [14]. Unfortunately we did not have injectable voriconazole available in our hospital at the time, hence the use of amphotericin B.

\section{Conclusion}

This case illustrates that E. oligosperma can be pathogenic intraocularly and could embark on a slow but destructive course. The organism is slow to culture, difficult to treat and the use of steroids should be avoided. A high index of suspicion for a fungal keratitis should be entertained in an incisional wound infiltrate, and an early biopsy should be considered, especially with an atypical presentation. Aggressive antifungal therapy with early surgical intervention should be instituted when this fungus is suspected.

\section{Abbreviations \\ IOL: Intraocular lens; MIC: Minimum inhibitory concentrations; VA: Visual acuity; PPV: Pars plana vitrectomy; RAPD: Relative afferent pupil defect; BLAST: Basic local alignment search tool; MIC: Minimum inhibitory concentrations}

\section{Aknowledgements}

None.

Authors' contributions

All authors contributed to project conception and critical review of the manuscript. The authors read and approved the final manuscript. The authors are alone responsible for the content of this article. 
Availability of data and materials

Not applicable.

\section{Declarations}

Ethics approval and consent to participate

Not applicable.

\section{Consent for publication}

Written consent was given by the patient for the publication of this case report.

\section{Competing interests}

No author has any conflict of interest to disclose.

\section{Author details}

${ }^{1}$ Division of Ophthalmology, Tygerberg Academic Hospital, University of Stellenbosch, Cape Town, South Africa. ${ }^{2}$ Division of Medical Microbiology and Immunology, Department of Pathology, Faculty of Medicine and Health Sciences, Stellenbosch University and National Health Laboratory Service, Tygerberg Hospital, Cape Town, South Africa.

Received: 29 January 2021 Accepted: 28 November 2021

Published online: 23 December 2021

\section{References}

1. White TJ, Burns TD, Lee SB et al (1990) Amplification and direct sequencing of fungal ribosomal RNA genes for phylogenetics. In: Innis MA, Gelfand DH, Sninsky JJ, White TJ (eds) PCR Protocols: a guide to methods and applications. Academic Press, New York, pp 315-322

2. Altschul SF, Gish W, Miller W, Myers EW, Lipman DJ (1990) Basic local alignment search tool. J Mol Biol 215(3):403-410. https://doi.org/10.1016/ S0022-2836(05)80360-2

3. Durand ML (2017) Bacterial and fungal endophthalmitis. Clin Microbiol Rev 30:597-613

4. Hanscom TA (2004) Postoperative endophthalmitis. Clin Infect Dis 38: 542-546

5. Lemley CA, Han DP (2007) Endophthalmitis: a review of current evaluation and management. Retina 27:662-680

6. American Academy of Ophthalmology (2018) 2018-2019 Basic and Clinical Science Course, Section 09. Amer Acad Ophthalmo Ch 8:261-263

7. Anand A, Therese K, Madhavan H (2000) Spectrum of aetiological agents of postoperative endophthalmitis and antibiotic susceptibility of bacterial isolates. Indian J Ophthalmol 48(2):123-128

8. Wykoff C, Flynn H, Miller D et al (2008) Exogenous Fungal Endophthalmitis: Microbiology and Clinical Outcomes. Ophthalmology 115(9):1501-1507.e2

9. Pflugfelder S, Flynn H, Zwickey T et al (1988) Exogenous fungal Endophthalmitis. Ophthalmology 95(1):19-30. https://doi.org/10.1016/S01616420(88)33229-X

10. Cordero R, Casadevall A (2017) Functions of fungal melanin beyond virulence. Fungal Biol Rev 31(2):99-112. https://doi.org/10.1016/j.fbr.201 6.12 .003

11. Chowdhary A, Perfect J, de Hoog G (2014) Black molds and Melanized yeasts pathogenic to humans. Cold Spring Harbor Perspect Med 5(8): a019570. https://doi.org/10.1101/cshperspect.a019570

12. Byrne D, Reboli A (2017) Rare yeast infections: risk factors, clinical manifestations, treatment, and special considerations. Curr Clin Microbiol Rep 4(4):218-231. https://doi.org/10.1007/s40588-017-0073-7

13. Chakrabarti A, Shivaprakash M, Singh R et al (2008) Fungal Endophthalmitis. Retina 28(10):1400-1407. https://doi.org/10.1097/IAE.0b013e318185e943

14. Homa M, Manikandan P, Saravanan V, Revathi R, Anita R, Narendran V, Panneerselvam K, Shobana CS, Aidarous MA, Galgóczy L, Vágvölgyi C, Papp T, Kredics L (2018) Exophiala dermatitidis Endophthalmitis: case report and literature review. Mycopathologia 183(3):603-609. https://doi.org/10.1007/ s11046-017-0235-4

15. Vicente A, Pedrosa Domellöf F, Byström B (2017) Exophiala phaeomuriformis keratitis in a subarctic climate region: a case report. Acta Ophthalmol 96(4): 425-428. https://doi.org/10.1111/aos.13624

16. Ozdemir $\mathrm{H}, \mathrm{Oz} Y$, Ilkit M et al (2012) Antifungal susceptibility of ocular fungal pathogens recovered from around the world against itraconazole, voriconazole, amphotericin B, and caspofungin. Med Mycol 50(2):130-135 https://doi.org/10.3109/13693786.2011.584328

17. Sav H, Ozdemir H (2016) Altınbas R, et al virulence attributes and antifungal susceptibility profile of opportunistic Fungi isolated from ophthalmic infections. Mycopathologia 181(9-10):653-661. https://doi.org/10.1007/s1104 6-016-0018-3

18. Narang S, Gupta A, Gupta V, Dogra MR, Ram J, Pandav SS, Chakrabarti A (2001) Fungal Endophthalmitis following cataract surgery: clinical presentation, microbiological Spectrum, and outcome. Am J Ophthalmol 132(5):609-617. https://doi.org/10.1016/S0002-9394(01)01180-1

19. Hariprasad SM, Mieler WF, Lin TK, Sponsel WE, Graybill JR (2008) Voriconazole in the treatment of fungal eye infections: a review of current literature. Br J Ophthalmol 92(7):871-878. https://doi.org/10.113 6/bjo.2007.136515

\section{Publisher's Note}

Springer Nature remains neutral with regard to jurisdictional claims in published maps and institutional affiliations.

\section{Submit your manuscript to a SpringerOpen ${ }^{\circ}$ journal and benefit from:}

- Convenient online submission

- Rigorous peer review

- Open access: articles freely available online

- High visibility within the field

- Retaining the copyright to your article

Submit your next manuscript at $\boldsymbol{\nabla}$ springeropen.com 